\title{
Comparative Study of Global Seismicity on the Hot Engine Belt and the Cooling Seismic Belt-Improvement on Research Ideas of Earthquake Prediction
}

\author{
Lijun Chen, Xiaofeng Chen, Fangfang Wan, Pinzhong $\mathrm{Li}^{*}$, Lei Shao \\ Earthquake Administration of Hunan Province, Changsha, China \\ Email: ${ }^{*}$ li_pin_zhong@tom.com
}

Received 2 June 2015; accepted 20 July 2015; published 27 July 2015

Copyright (C) 2015 by authors and Scientific Research Publishing Inc.

This work is licensed under the Creative Commons Attribution International License (CC BY).

http://creativecommons.org/licenses/by/4.0/

$$
\text { c) } \underset{\mathrm{EY}}{\mathrm{i}} \text { Open Access }
$$

\begin{abstract}
The study in this paper analyzes and compares the distribution on the global engine active seismic zone and cooling seismic belt basing on the ANSS earthquake catalog from Northern California Earthquake Data Center. An idea of the seismogenesis and earthquake prediction research is achieved by showing the stratigraphic structure in the hot engine belt. The results show that the main engine and its seismic cones are the global seismic activity area, as well as the subject of global geological disaster. Based on the conjecture of other stratum structure, the energy of crustal strong earthquake and volcano activities probably originates from the deep upper mantle. It is suggested that the research on earthquake and volcano prediction should focus on the monitor and analysis on the sub-crustal earthquake activities.
\end{abstract}

\section{Keywords}

The Hot Engine Belt, the Cooling Seismic Belt, Seismic Cone, Seismo-Geothermics Theory, Earthquake Prediction

\section{Introduction}

It has been commonly accepted that the cause of earthquakes is mainly due to the strain energy accumulation of surface tectonics. However, the statistical analysis and comparative study of the seismic activities in the hot engine belt and the cooling seismic belt indicate that the energy of crustal strong earthquake and volcano activities

"Corresponding author. 
may be derived mainly from the deep of the upper mantle. Therefore, the forecast of earthquake and volcano may turn to focus on monitoring and studying the sub-crustal earthquakes.

In the Seismo-geothermics theory [1], the global state of seismic activities and volcano activities can be devised into two big tectonic systems, the hot engine belt and the cooling seismic belt respectively.

Specific division method:

First of all, by using the ANSS catalogue [2] accessed through the Northern California Earthquake Data Center, and according to the centers of deep seismic activity, 24 seismic cones were divided [1] [3], including No. 01-South Chile seismic cone, No. 02-North Chile cone, No. 03-Guatemala cone, No. 04-Haiti cone, No. 05-Bering Sea cone, No. 06-Okhotsk Sea cone, No. 07-Japan cone, No. 08-Chinese Huichun cone, No. 09-Northern Mariana cone, No. 10-South Mariana cone, No. 11-Taiwan and Ryukyu cone, No. 12-Philippines cone, No. 13-Salomon cone, No. 14-West Tonga cone, No. 15-East Tonga cone, No. 16-Indonesia cone, No. 17-Burma cone, No. 18-Hindu Kush cone, No. 19-Mediterranean cone, No. 20-West Mediterranean cone, No. 21-The South Sandwich cone, F1—Manila cone, F2—Andaman cone and F3-North America cone, as shown in Figure 1.

Seismic cone (once called as seismic cylinder or seismic mantle plume) is a kind of column of inverted cone, which is from intensive deep earthquakes, and the depth is up to approximately $740 \mathrm{~km}$.

Secondly, as shown in Figure 1, the 24 cones are surrounded by pale yellow block, and therefore are called hot engine belt. Due to the depth of the earthquake activities in Atlantic ridge between No. 20 cone and No. 21 cone is more than $50 \mathrm{~km}$, the two cones could be connected imaginary. Therefore, the above connected engines with 24 seismic cones constitute a complete M type belt.

The seismic activity beyond the pale yellow block is referred to as so-called cooling seismic zone. These earthquakes are mainly distributed along the 4 Ocean ridges showing with green belt in Figure 1. Other earthquakes are rarely scattered besides the above two zones. The Atlantic Ocean ridge, the India Ocean ridge and the Pacific Ocean ridge are shown with W type distribution on the Earth, calling W type cooling seismic belt.

\section{The Characteristics and Relationships of the Seismic Activity in the Hot Engine Belt and the Cooling Seismic Belt}

\subsection{Seismic Activity Distribution of the Hot Engine Belt and the Cooling Seismic Belt}

Based on the ANSS earthquake catalog, the global total records of earthquakes M4+ are 388,775 from January,

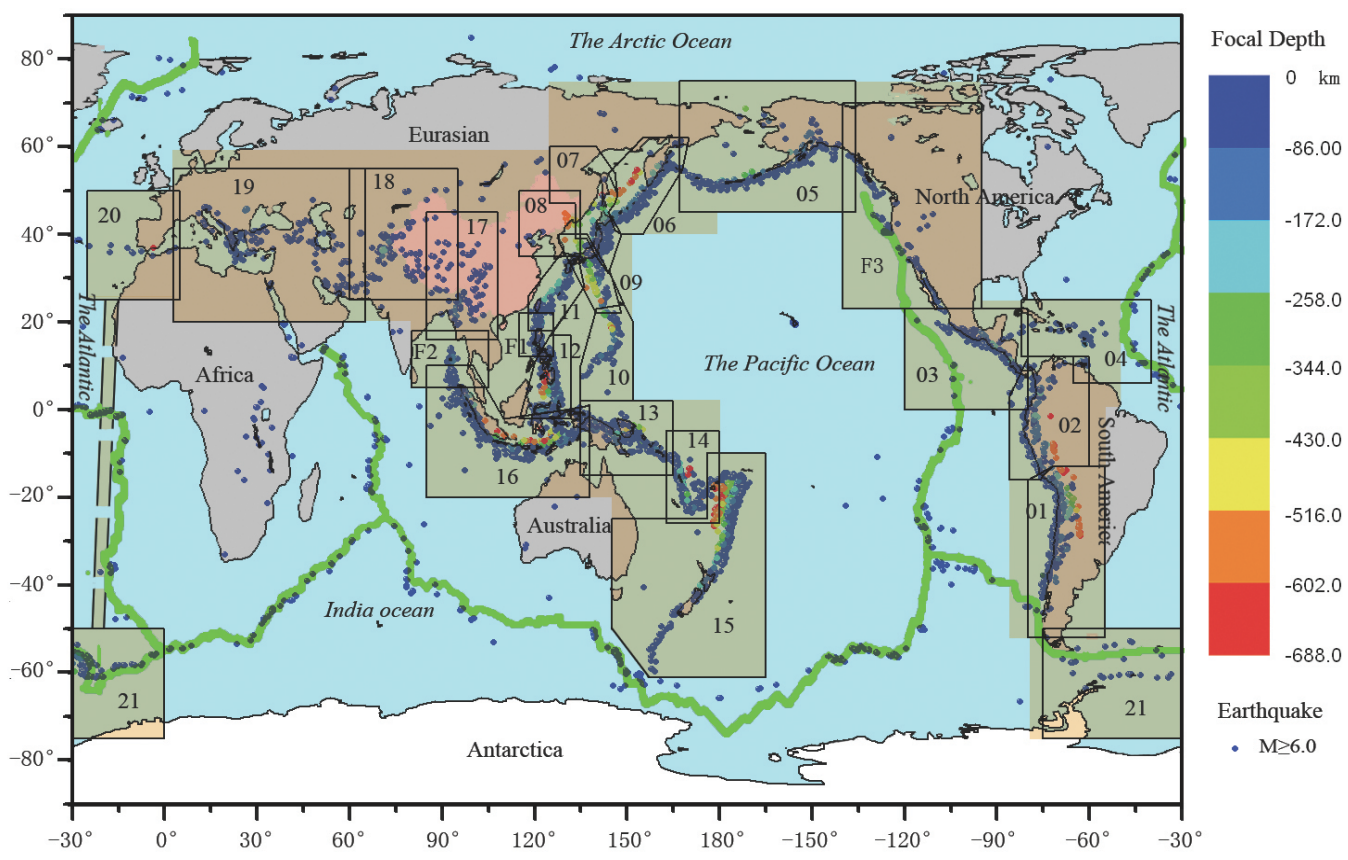

Figure 1. Division of the hot engine belt and the cooling seismic belt on the Earth. 
1963 to March, 2015. The records in the hot engine belt are 359,528, accounting for $92.477 \%$ of total global earthquakes, and the maximum depth is $735.8 \mathrm{~km}$; the records in the cooling seismic belt are 29,247, accounting for $7.523 \%$ of total global earthquake, and the focal depth of $99.7 \%$ earthquakes is less than $40 \mathrm{~km}$.

The frequency of global seismic activity in the hot engine belt and the cooling seismic belt is analyzed in Table 1 and a schematic diagram of the data listing in Table 1 is showed in Figure 2. According to Table 1 and Figure 2, it is indicated that the hot engine belt is the most active belt on the Earth.

Figure 3 shows the corresponding curves of the earthquake recurrence rate. It can be seen that the recurrence rate curves of the hot engine belt are almost coincide with the global earthquakes, while the repetition rate curve of the cooling seismic belt is greatly deviate from the above two curves. The slope (b value) of the cooling seismic belt is significantly higher than the slope of hot belt, indicating their significant difference in the activity level.

As shown in Figure 3, it is also indicated that the earthquake records of less than M5 in the ANSS catalog are not complete due to the monitoring ability of global seismic network.

\subsection{Seismic Activity STATUS of the Hot Engine Belt and the Cooling Seismic Belt}

The change of the annual frequency of seismic activities N/A on the hot engine belt and the cooling seismic belt

Table 1. Statistics of seismic activity frequency in the hot engine belt and the cooling seismic belt.

\begin{tabular}{|c|c|c|c|c|c|}
\hline \multirow{2}{*}{ Magnitude } & \multirow{2}{*}{ Global } & \multicolumn{2}{|c|}{ The hot engine belt } & \multicolumn{2}{|c|}{ The cooling seismic belt } \\
\hline & & Frequency & $\%$ & Frequency & $\%$ \\
\hline $4.0-4.9$ & 307,504 & 286,090 & 93.04 & 21,414 & 6.96 \\
\hline $5.0-5.9$ & 75,240 & 67,906 & 90.25 & 7334 & 9.75 \\
\hline $6.0-6.9$ & 5432 & 4948 & 91.09 & 484 & 8.91 \\
\hline $7.0-7.9$ & 564 & 550 & 97.52 & 14 & 2.48 \\
\hline $8.0-8.9$ & 33 & 32 & 96.97 & 1 & 3.03 \\
\hline $9.0-9.9$ & 2 & 2 & 100.00 & - & - \\
\hline Sum & 388,775 & 359,528 & 92.477 & 29,247 & 7.523 \\
\hline
\end{tabular}

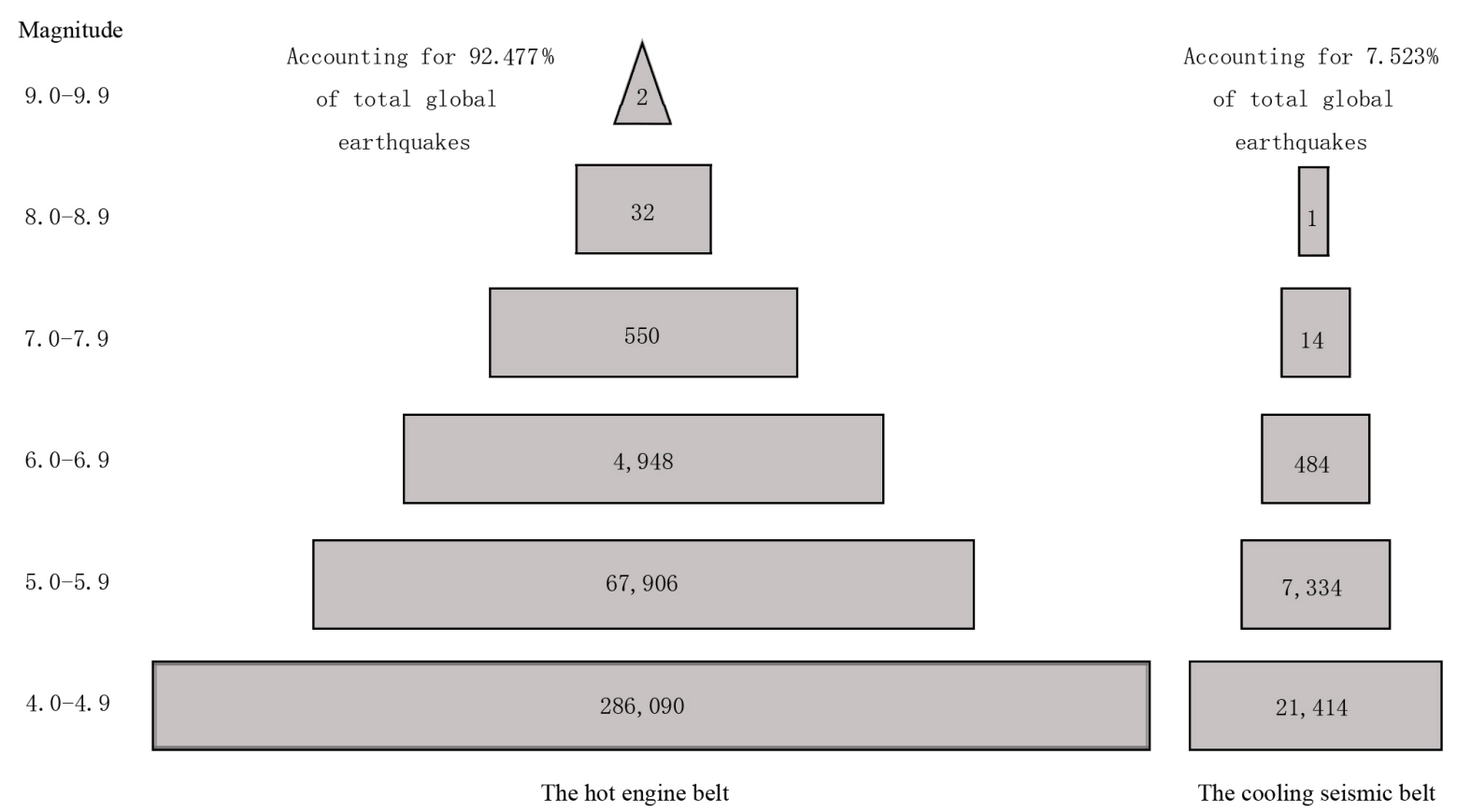

Figure 2. Seismic activity intensity distribution of the hot engine belt and the cooling seismic belt. 


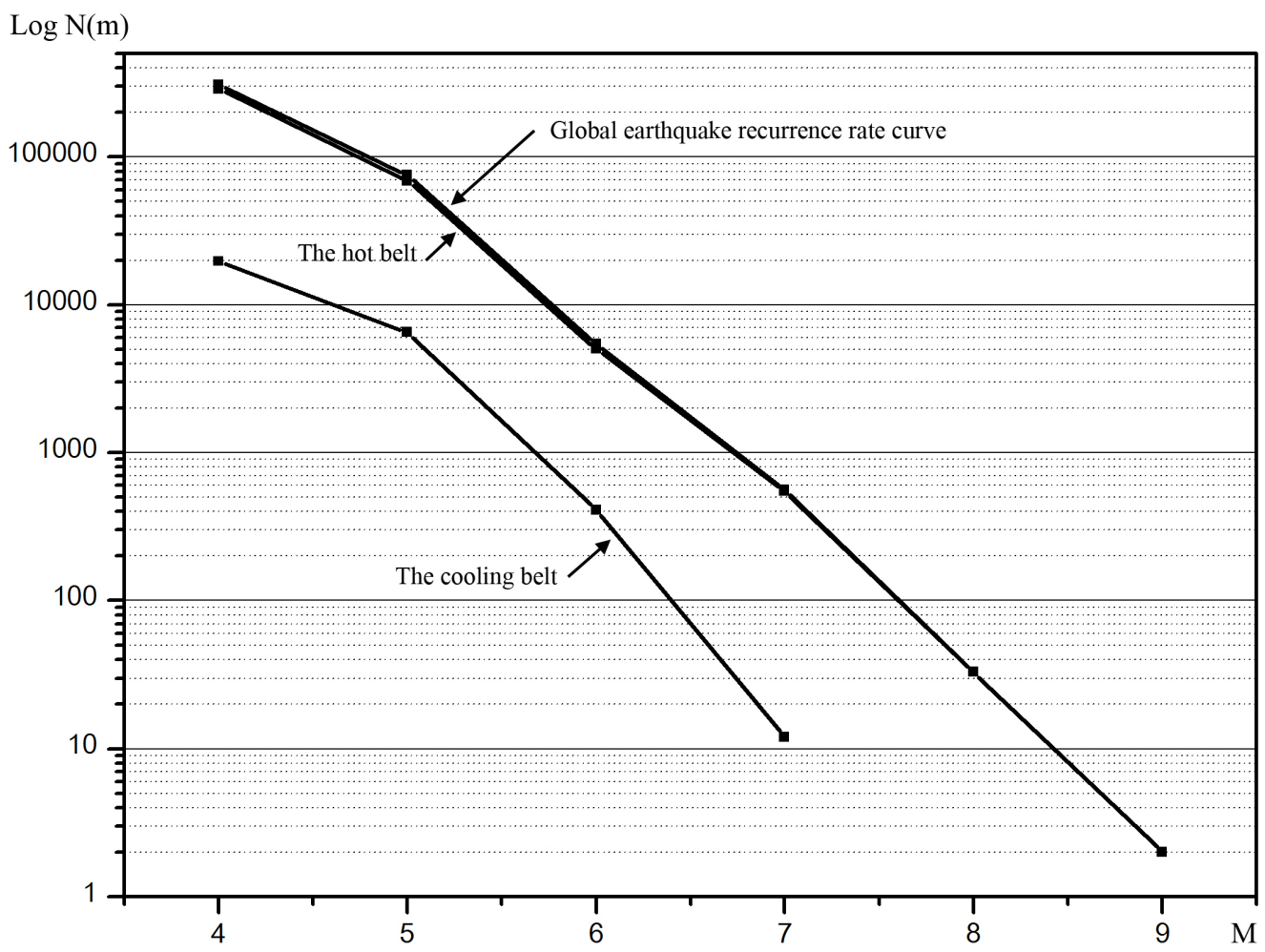

Figure 3. The seismic repetition rate curves of the hot engine belt and the cooling seismic belt.

as function of time is shown in Figure 4. As shown in Figure 4, although the annual frequencies of the two belts are very different, the trend of the change is consistent, revealing that their activities are subject to the same control factors.

\subsection{The Layer Structure of Seismic Activities in the Hot Engine Belt}

The seismic activity in the hot engine belt has a lot of deep earthquakes, with $35.50 \%$ of earthquakes depth below $50 \mathrm{~km}$ in the total earthquakes of hot engine belt.

The distribution with focal depth of frequency $\mathrm{N}(\mathrm{h})$ in the hot engine belt is shown in Figure 5 .

As comparison, the distribution with focal depth of seismic strain energy is cumulative calculation according the general formula of strain energy:

$$
\varepsilon(h)=\sum_{k=0}^{n-1} 10^{\left(4.8+1.5 M_{k}\right) / 2}, \quad\left(\mathrm{~J}^{1 / 2}\right)
$$

where $M$ is a parameter of magnitude. Although $M s, M b, M w, M_{\mathrm{L}}$ and other magnitude scales are listed in the ANSS catalog, we will use a unified Ms as the estimated magnitude value for all magnitude scales conducting the first approximation. The value $h$ is the focal depth divided into $50 \mathrm{~km}$ each.

The distribution of strain energy with focal depth is shown in Figure 6, which shows almost the same distribution comparing to Figure 5.

Based on the analysis of Figure 5 and Figure 6, the deep zone in the hot engine belt can be seemly divided into a number of layered structures:

The first layer of the depth of $0-50 \mathrm{~km}$ is the dissipative layer, where earthquake and volcano energy release in the crust.

The second layer of the depth of 50 - $150 \mathrm{~km}$ is generally recognized as lava sac, or it can be called the energy storage layer. The accumulated hot energy in this layer passes from the deep part and readily promotes earthquake and/or volcanic activities to release stored energy.

The third layer of the depth of $150-300 \mathrm{~km}$ is sub active layer. This layer contains seismic post launch layer of lower seismic cones, such as No. 03 , No. 04 , No. 11, No. 17, No. 18, No. 19, No. 21, F1, F2 cone, etc. The 


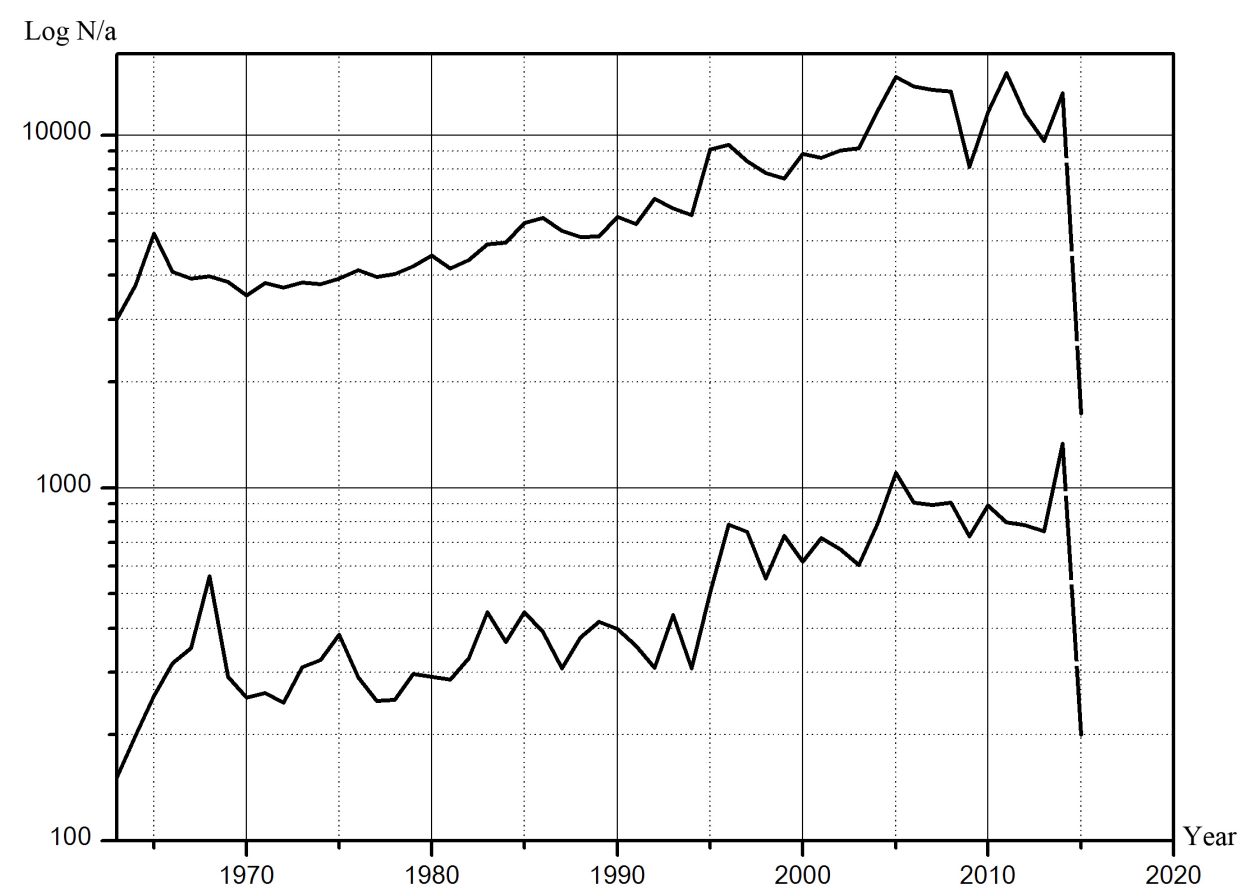

Figure 4. The annual frequency curve of seismic activities on the hot engine belt and the cooling seismic belt.

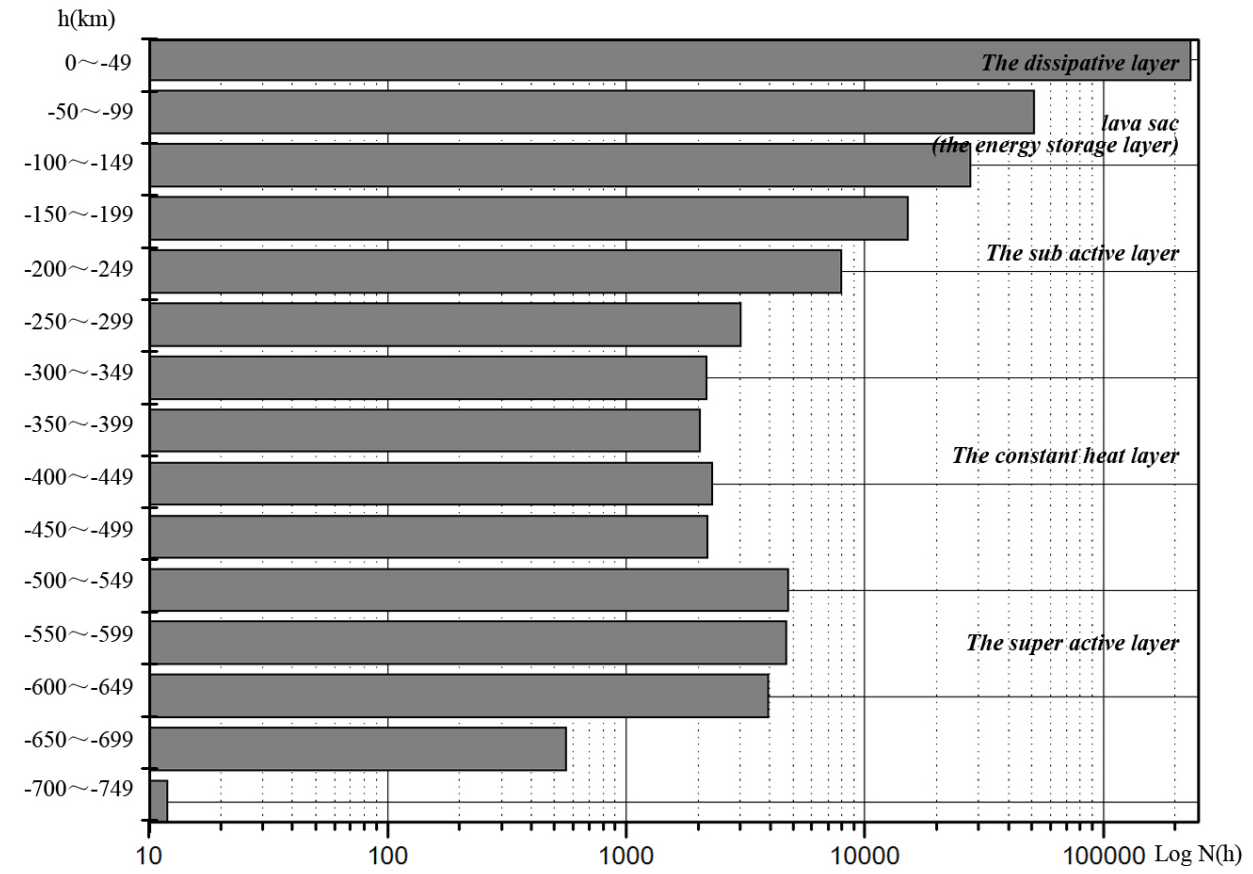

Figure 5. The distribution of earthquake frequency with focal depth in the hot engine belt.

maximum earthquake focal depth of all the lower cones is approximately $300 \mathrm{~km}$. However, there are exceptions, such as F3, the North American seismic cone. According to the earthquake catalogue magnitude above 4, the maximum depth of F3 is $98 \mathrm{~km}$. But if based on the catalog of magnitude above 2 in North America, its depth is more than $600 \mathrm{~km}$. The Italy branch of cone No. 19-Mediterranean seismic cone belongs to the same case as well. 


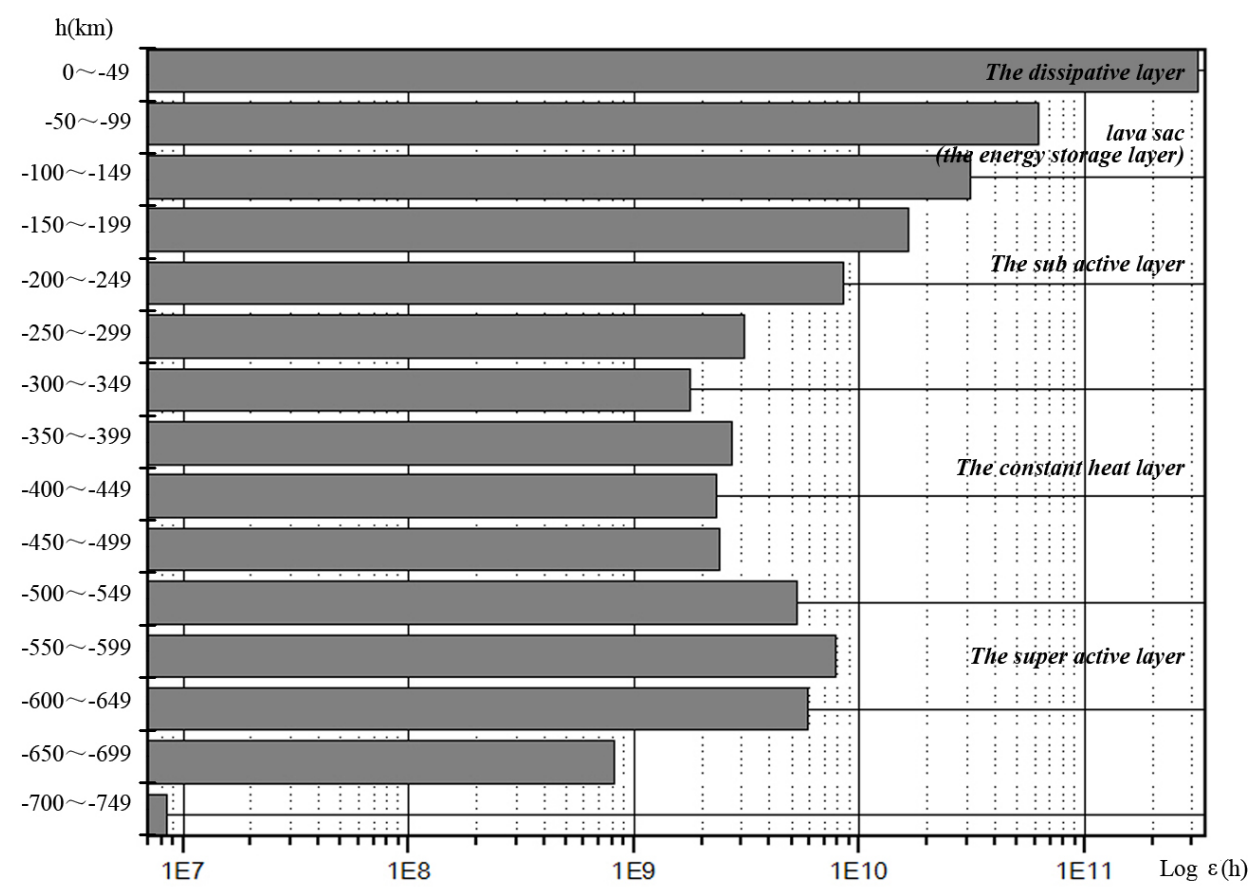

Figure 6. The distribution of earthquake Strain energy with focal depth in the hot engine belt.

The fourth layer is $300-500 \mathrm{~km}$ calling the constant heat layer. The seismic activity in this layer is relatively stable because the excess hot can directly pass through. Therefore, the earthquakes in this layer in some super cone are less active.

The fifth layer is the super active layer with depth of more than $500 \mathrm{~km}$. This layer contains the post launch of super seismic cones, including cone No. 01 , No. 02 , No. 05 , No. 06 , No. 07 , No. 08 , No. 09 , No. 10 , No. 12 , No. 13, No. 14, No. 15 and No. 16. The maximum earthquake focal depth of the super cones is above $600 \mathrm{~km}$ and even can reach to about $740 \mathrm{~km}$.

\subsection{The Relationship of the Hot Engine Belt and the Cooling Seismic Belt}

The hot engine belt of type $\mathrm{M}$ and the cooling seismic belt of type $\mathrm{W}$ are distributed face to face on the surface of the Earth with phase shifting by approximately longitude 90 degrees. It seems that they are two big tectonic belts controlled by the self-rotation of the Earth and/or that with outer space effect. Therefore, their relations are inseparable. However, the activity of the hot engine belt is related to the security of humankind and therefore is the most concerned problem.

Due to exist of a large number of deep earthquake activities, which can bring lots of heat from deep mantle to the surface, the hot engine belt is known as the engine. However, some people issues that the volcano activity in the cooling seismic belt is also "hot". In fact, the relationship of the hot belt and the cooling seismic belt seems to be analogy for cylinder and the exhaust pipe of the vehicle engine, in which the hot belt is a power system, and the cooler belt is a cooling system. Two "hot" and "cold" terms are only relative. Thus, it is indicated that the hot belt is a disaster zone where the catastrophic effect will bring in the cooling seismic belt to get a response in order to achieve the balance and regulation of the Earth's hot energy.

\section{Discussion and Conclusions}

\subsection{Discussion}

More detailed meditation could be brought through our comparative study of the hot engine belt and the cooling seismic belt.

1) About $92.5 \%$ of earthquake magnitude $4+$ and $97.5 \%$ of the earthquake magnitude $7+$ in global happened in the hot engine belt. According to the incomplete statistical analysis, more than $87 \%$ of the active volcanoes 
around the world locate in the hot engine belt. Therefore, the hot engine belt acting as a global geological disaster zone locating in the most populous areas in the world will create more threat to human society.

2) The immediate culprit for so strong earthquakes and volcanism in the hot engine belt should be attributed to the deep source seismic activities in the hot engine belt. It can be deduced but not certain that the activity of deep source earthquakes does never depend on the accumulation of strain energy from surface tectonic movement. On the contrary, the energy produced from deep source seismicity is unable to dissipate in the deep mantle. It can only transmit to the cryogenic upper-layer, layer by layer from the bottom to the top and therefore resulting in the seismic energy accumulation in the upper layer. Based on the rough deduction of this study, the strain energy released by sub-crustal earthquakes acting over $50 \mathrm{~km}$ in depth, takes about $47.12 \%$ of the strain energy released by the movement from all crustal earthquakes. Furthermore, if the thermal convection rising along with the deep source seismicity is considered, the energy stored in lava sac is large enough to motivate the crustal strong earthquake and volcanic activities after fluctuant accumulation in a time of Mantle Decadal Oscillation (MDO) [4].

It can be understandable that the heat convection rises via the boiling water experiment [1]. When heating water, the increasing heat does not completely by the bubble burst bringing the heat upwelling. It is actually attributed to the convection. Therefore, the earthquake activity from the intermediate and deep source only presents one kind of surface appearance of the thermal activity in upper mantle instead of all the energy accumulated in the lava sac.

3) It is a challenge to the traditional views on the seismic activity, which are the result of accumulating strain energy from land surface tectonic movement. During the past, it is thought that weak tectonic earthquake was caused by tectonic movement strain energy accumulating from tectonic system, and later weak tectonic earthquake was caused by strain energy accumulating from plate movement. However, both the tectonics system and plate movement on the earth surface can be divided out with numerous small or large plates or active blocks. Why does the majority of earthquakes and volcanic activity only locate in the hot engine belt? Moreover, in any case, the strain energy accumulating from surface tectonic movement will not be able to motivate a deep source earthquake over $600 \mathrm{~km}$ in depth.

In contrast, shallow earthquake activity in the cooling seismic belt, except volcanic earthquakes, is perhaps mainly by strain energy accumulation of crustal tectonic activities, so is the role to adjust and balance with activities in the hot engine belt. However, strong earthquake activity in the cooling seismic belt is few, even if there is no social significance to earthquake prediction.

4) Based on these reasons, the authors suggest that the traditional view of earthquake prediction research should be transfer to study and monitor the sub-crustal earthquake activity ${ }^{1}$. For this purpose, the authors submitted "Advice on improving the work of earthquake prediction in our country" in 2014. So far, the best monitoring work on sub-crustal earthquake should belong to the central south region of North America and Mediterranean region, and great progress has been made in the northern of Xinjiang region in China recently [5] [6]. The authors had predicted that magnitude 6.9 earthquake happened in California Bay on April 12, 2012 by using the catalog of south-central North America $[7]^{2,3}$, and had deduced the possibility of $\mathrm{M}>6$ earthquakes in Italia two times in 2009 and in 2012 by using the Mediterranean M > 2 earthquakes catalog [8] (English version, unpublished); More, the authors also had deduced the possibility of M 6.6 Xinyuan earthquake in northern Xinjiang of China in 2012 by using the $M>2$ earthquake catalog for north Xinjiang, China [9] and had made prediction to global crustal strong earthquake and volcanic activity within next three years (from 2012 to 2015) by using global $\mathrm{M}>4$ earthquake catalog (Formal predict card-0419 Card) [10] [11]. Good results have been achieved based on above predictions.

The Seismo-geothermics prediction method with the analysis of the time series for hypocenter depth in seismic cones, combining the space distribution for the sub-crustal earthquake activity can roughly predict the timeframe, location and approximate magnitude of the crustal earthquake and volcanic activity by several months in advance [12].

5) There are two key points should be noted on monitoring the sub-crustal earthquake activity. Firstly, the

\footnotetext{
${ }^{1}$ Chen, L.J. (2013) Study on the Global Shell Seismic Activity. Hunan Journal of Seismology (Internal Magazine), Serial 35, 5-13.

${ }^{2}$ Chen, L.J. and Chen, X.F. (2012) Prediction of USA West Coast Earthquakes. Hunan Journal of Seismology (Internal Magazine), Serial 34, 1-6.

${ }^{3}$ Chen, L.J., Chen, X.F., Wan, F.F. and Ouyang, C.X. (2013) The Earthquake Prediction Method Research in the West Coast of the United States. Hunan Journal of Seismology (Internal Magazine), Serial 35, 90-98.
} 
earthquake observation network in the main area on the hot engine belt should be set reasonably, by monitoring $M>2$ earthquakes effectively. Secondly, the unified global protocols and the crustal structure model should be established via the determination of the hypocenter depth.

Among the data collected by the author from the determination results on hypocenter depth, only the data from central southern region of North America, the Mediterranean region in Europe and the northern Xinjiang region in China Xinjiang are useful. All of the three regions include the $M>1$ earthquake data in the earthquake catalog, which are comparative on the hypocenter depth data. Certainly, the measurement of hypocenter depth does not need be absolutely accurate but should be comparative mutually at least during this moment.

6) So far, it is still much difficult to predict the earthquake no matter which way is taken for earthquake prediction research. The most difficult thing is that $\mathrm{M}>7$ crustal strong earthquakes happened suddenly like volcanic eruption does. Therefore, it is nearly impossible to find a decent earthquake "precursor" whenever any crustal strong earthquake happened. The sub-crustal earthquake activity is probably "suffocate" due to the earthquake source body's locking before an earthquake. Predicting the coming earthquake is just like catching the instant in the experiment of "Water sounding, but not boiling", which happens in a flash [1].

However, regardless of the earthquake energy coming from crust or deep mantle, the crustal earthquake implacably requires both the crustal seismic tectonics and various geophysical field effects, which will inevitably result in the macroscopic anomaly of the sound, light, electricity, underground water, animals, etc.

Therefore, it will be indispensable to strengthen the research of seismic structure, geophysical field, macroscopic anomaly impending earthquake, and even the earthquake warning system. In addition, it is extremely important to popularize the knowledge of earthquake science and work of seismic fortification.

\subsection{Conclusions}

In summary, based on the working method of the Seismo-geothermics theory and the ANSS earthquake catalogue of Northern California Earthquake Data Center, this article has developed the concept of hot engine belt and cooling seismic belt by using seismic cone as the tectonic units and statistical units of analysis, as well as the common features from the basic features of earthquake activities of various seismic cone. Also, with the comparison and study of the sub-crustal stratum structure and seismic activity of hot engine belt and cooling seismic belt, this article raises the discussion of seismogenesis and earthquake prediction, which will be the foundation of earthquake prediction and volcano prediction of the Seismo-geothermics theory.

The results suggest that the hot engine belt and its contained seismic cones are the major subjects of the global seismic activity, as well as the major subjects of the global geological disaster. Based on the conclusion of the stratum structure, the crustal earthquake and the volcanic energy may likely come from deep upper mantle. Therefore, the puzzled earthquake prediction may be solved probably by changing the research directions of earthquake prediction and volcano activities, and strengthening the monitoring and study for sub-crustal earthquake.

\section{Acknowledgements}

The ANSS catalog for this study was accessed through the Northern California Earthquake Data Center (NCEDC), doi:10.7932/NCEDC.

\section{References}

[1] Chen, L.J. (2012) Theory and Application of Seismo-Geothermics. Inland Earthquake, 26, 108-122.

[2] NCEDC (2014) Northern California Earthquake Data Center. UC Berkeley Seismological Laboratory. Dataset doi:10.7932/NCEDC.

[3] Chen, L.J. (2013) Concept and Basic Characteristics of Seismic Cylinder. South China Journal of Seismology, 33, 114.

[4] Chen, L.J. (2013) Mantle Decadal Oscillation (MDO). http://blog.sciencenet.cn/blog-552558-665664.html

[5] Wang, H.T., Li, Z.H., Zhao, C.P. and Qu, Y.J. (2007) Relocation of the M s $\geq 2.0$ Earthquakes in the Northern Tianshan Region, Xinjiang, Using Double Difference Earthquake Relocation Algorithm. Earthquake Research in China, 23, 47-55.

[6] Long, H.Y., Xu, Y., Wei, B. and Xu, H.X. (2005) The Velocity Model of P Wave and the Location of Small Earth- 
quakes in Kashi-Wuqia Arer of Xinjiang. Inland Earthquake, 19, 16-21.

[7] Chen, L.J. (2012) Earthquake Prediction Verification Record 001: The Earthquake M 6.9 in 4.12 in the Gulf of California. http://blog.sciencenet.cn/blog-552558-558624.html

[8] Chen, L.J. (2013) The Crime Incident in Italy Earthquake Prediction. http://blog.sciencenet.cn/blog-552558-652328.html

[9] Chen, L.J. (2014) To Explore the Causes of Strong Earthquakes in Tianshan Area-As An Example of Xinyuan Earthquake M6.6 in June 30, 2012. http://blog.sciencenet.cn/blog-552558-829373.html

[10] Chen, L.J. (2015) Explanation of the 0419 Card of the Earthquake and Volcano Prediction in the World's Major Seismic Cones Within 3 Years. http://blog.sciencenet.cn/home.php?mod=space\&uid=552558\&do=blog\&id=883826

[11] Chen, L.J. (2015) The Test Summary for 0419 Forecast Card in 2012 (Online Version). http://blog.sciencenet.cn/home.php?mod=space\&uid=552558\&do=blog\&id=894296

[12] Chen, L.J. (2015) Pakistan Earthquake with Ms 7.7 in 2013 and Causative Structure of Hindu Kush. Inland Earthquake, 29, $15-27$. 